Hyland KL Student perceptions of hidden messages in teacher written feedback, Studies in Educational Evaluation, 2013, v. 39(3) p. 180-187

\title{
Student perceptions of hidden messages in teacher written feedback.
}

\section{Introduction}

Teachers' written feedback is potentially a powerful influence on learning and achievement in higher education. It is typically highly valued by students and provides teachers with the opportunity to offer the kind of individualized attention that is otherwise rarely possible under classroom conditions. But while the goal of the feedback might be to provide students with information on how well they have understood the course content, not all the messages conveyed are explicit or, indeed, related to the work at hand. In fact, both the content of their feedback and the ways they respond can inform students of their tutors' beliefs about their subject, about learning, and about the value of literacy in their disciplines. This information is particularly important to second language students studying in English as they are often uncertain of their writing and the importance they need to give to it when studying their disciplines. While almost all English medium universities around the world now require students to gain credit in academic English courses which place a heavy emphasis on writing, it is unclear how far this emphasis is repeated in the ways subject tutors respond to student writing.

It is through feedback, however, that tutors are able to convey, whether deliberately or inadvertently, messages which can influence students' attitudes to their field of study, to their progress and to themselves. Because feedback is very closely linked with student achievement, retention and progression (Bloxham and Boyd, 2007; Yorke, 2003) the messages students take from feedback becomes an important aspect of learning. The aim of this paper is therefore to ascertain what messages a group of second language undergraduates at a Hong Kong university recover from their tutors' feedback practices. In particular, I seek to discover: 
1. What do teachers' convey to students about the importance of language and writing?

2. What do they convey about the importance of feedback?

3. What do they convey about the teacher-student relationship?

\section{Teacher feedback and student perceptions}

Feedback is widely believed to be central to student learning and achievement and perhaps almost as important as direct instruction and students' prior cognitive abilities (Hattie \& Timperley, 2007). By encouraging and consolidating disciplinary understandings, intellectual development and writing improvement, the guidance of expert others provides scaffolded support for learners (Vygotsky, 1978). Feedback offers the writer an outsider's view of a text and so provides a sense of audience and what that audience values in writing, contributing to his or her acquisition of disciplinary subject matter and patterns of argument and evidence. An increasing body of evidence, however, questions its effectiveness (e.g. Price, Handley, Millar \& O'Donovan, 2010) and student surveys in higher education show feedback to be an area of tensions between staff and students as universities grapple to provide effective teaching practices in resource-constrained environments.

The full extent of student dissatisfaction is revealed in student surveys in the UK, Australia and Hong Kong (e.g. Krause et al, 2005; Carless, 2006). There seems little doubt of students' thirst for teacher comments on their work (Hyland, 2010), although they also report feedback to be one of the most problematic aspects of their learning experience (e.g. Pokorny \& Pickford, 2010). Students often, for example, say they find it difficult to understand (e.g. Weaver, 2006), lacking in specifics (Higgins, Hartley \& Skelton, 2001), or hard to act on (Walker, 2009). Weaver's (2006) Business and Art \& Design students, for instance, felt a lot of feedback was negative, unrelated to assessment criteria and failed to provide any sense of direction. Scott, Badge and Cann (2009) found their second year bioscience students were dissatisfied with the utility and transferability of their feedback while Watty et al's (2011) accounting students were critical of the generality and lack of timeliness of their feedback. 
One positive area of learner perceptions is the explicit correction of written errors where students are using English to study in a second language. Here studies have found strong student support for corrective grammar feedback (e.g. Schulz, 2001) but the benefits of this may be limited to improvements in a subsequent draft rather than to longer term learning (Truscott \& Hsu, 2008). Truscott (1996) summarizes the research conducted in such contexts as suggesting that teacher feedback has little discernible effect on writing development, while Lea \& Street (2000) argue that feedback fails to convey the clear disciplinary values and preferences for organizing knowledge that tutors would wish for. Studies, in fact, have produced conflicting results, often because their experimental design removes feedback from the contexts in which it has meaning for students. It is likely, moreover, that students themselves understand their feedback in different ways depending on their backgrounds, their disciplines, their views of their teachers and their own abilities.

Correspondingly, the meanings teachers attach to feedback, the time they invest in it and the value they feel it has in instruction may be reflected in how they frame their comments, what they say (or don't say) and in the relational stance they choose to adopt. Like all texts, teacher feedback does not occur in a vacuum but is an expression of recognized social purposes and individual goals. In a study of Hong Kong secondary school teachers, for example, Lee (2008: 69) suggests that:

teachers' feedback practices are influenced by a myriad of contextual factors including teachers' beliefs, values, understandings, and knowledge, which are mediated by the cultural and institutional contexts, such as philosophies about feedback and attitude to exams, and socio-political issues pertaining to power and teacher autonomy.

In Higher Education it is similarly shaped by the teacher's pedagogic intentions, priorities and ideologies filtered through the academic and disciplinary culture within which it occurs. This is simply to say that all acts of communication are embedded in wider sociocultural beliefs and practices which selectively activate knowledge and prompt specific processes. 
In sum, while much of the research on feedback given to second language writers has focused on error correction (e.g. Ferris, 2006; Bitchener, 2008), feedback carries a heavier informational load than this, not all of which is directly pedagogic or even intentionally communicated. In fact, students receive various messages in the feedback they get on their work; messages about university values, about the role of writing in learning, about their identity as students and about their induction into disciplinary epistemologies. Some of this is accidentally communicated -information 'given off' rather than 'given' in Goffman's (1971) terms - and may not be consciously apparent to participants. Other messages, however, may be intentionally conveyed. What seems important here is what students recover from this feedback as this may have an impact on their attitudes to study and perhaps to their learning.

\section{Context, participants and procedures}

a) Context The study takes place in a leading research-intensive university in Hong Kong. Hong Kong universities use English as their medium of instruction and it is a compulsory subject from kindergarten onwards and some schools teach entirely in the English medium. Competence in written English in particular is crucial at university where assignments and examinations are in English. Students, however, are unfamiliar with academic writing conventions and have almost no knowledge of disciplinary argument practices. Moreover, despite the efforts of the local education authorities to initiate changes in teaching practices, traditional, transmission and exam dominated methods still prevail (Davison, 2007; $\mathrm{Hu}, 2005)$. Students are largely expected to be passive recipients of teacher-fed knowledge as they are drilled to meet the requirements of public exams. In these circumstances students are ill-prepared for the demands of university writing and the rhetorical expectations of particular fields of study. The ways particular wordings, argument patterns and forms of evaluation are marked as more or less institutionally appropriate remain mysterious to them. Nor are they socialized into an understanding that writing might be used as a mode of discovery and a means of learning and self-awareness. 
As a result, all students are required to attend two, 30 hour, English for Academic Purposes (EAP) courses at university for which they receive six credits. These courses largely address faculty-based writing practices and seek to bridge the English which students' have learnt at school and that which is required in their disciplinary studies.

b) Participants The study draws on interviews conducted with twenty four first and second year undergraduate students, six from each of four faculties (Business, Science, Engineering and Arts). The students were majoring in history, American studies, modern China studies, psychology, biology, biochemistry, chemistry, civil, mechanical and electrical Engineering, computer science, business, sociology, economics, politics, English, social administration and various combinations of these. Twenty two were Cantonese first language speakers and two from Mainland China, with Putonghua as their first language. The students were 12 males and 12 females aged between 18 and 20 and recruited at random from registration lists. Twenty had attended Chinese-medium primary and secondary schools and four had graduated from English-medium schools, but all were competent users of English at an intermediate to advanced level (around IELTS 6.5 and above).

c) Procedures To uncover students' experiences and beliefs in this context, each of the 24 students was interviewed twice. The first interview followed a semi-structured format with open-ended prompts to gather their perceptions of the literacy practices of their disciplines, their writing, and their experience of feedback, while the second involved more detailed discussion of particular pieces of writing which they had submitted for assessment. All interviews were recorded, transcribed verbatim, and entered into the qualitative software programme NVivo where data was coded and connections made. After several passes through the data and reference to actual feedback provided to the students on both their content and language course assignments, several themes emerged relating largely to how teachers gave feedback, what they commented on, and how much they wrote, identifying recurring, developing and significant patterns and themes. The analysis therefore involved moving from individual perceptions to common elements. The student responses were 
categorised into various themes and checked by a graduate research assistant and myself with an inter-rater agreement of kappa 0.8 . These categories formed the basis of the analysis discussed below.

\section{Results and discussion: Messages in feedback}

The interviews confirmed that most students believed that feedback can help them in their studies, but it is also clear that they saw this feedback varied enormously between teachers in terms of its quantity, focus, style and effectiveness. The interviews also showed that students come to notice discernible messages in this feedback that told them about the discipline they are studying, about its communicative practices, and about how they should engage with texts and lecturers. I should emphasize here that I am interested in how students interpreted the feedback they received rather than how it is intended. It is possible that tutors were unconscious of how their comments and practices were understood and may even disagree with these interpretations. There do, however, appear to be broad messages conveyed which transcend the idiosyncrasies of individual tutors and which are systematically patterned depending on discipline and whether they were given by a subject tutor or a language one.

In fact, it is possible to identify five broad themes in these messages, relating to:

1. the importance of language accuracy in academic writing

2. the role of writing in disciplinary communication

3. the role of writing in learning

4. the value of feedback in developing knowledge and skills

5. the nature of the teacher-student relationship

I will discuss the evidence for each of these themes in turn.

\section{The importance of language accuracy}


Hong Kong students arrive at university with ideas about language which have been shaped by seven years of schooling emphasizing the importance of accuracy in written English. While this provides them with a reasonably good grammatical knowledge, and often a certain anxiety about their writing competence, it also creates an understanding of texts as the application of rules rather than the expression of meanings. They have got through their secondary education by learning that good writing involves the correct arrangements of words, clauses and sentences and that teachers will correct every English error. These certainties are challenged in their undergraduate studies with mixed messages in the feedback they receive on their assignments.

All students take two English courses as part of their undergraduate requirements and, unsurprisingly, the feedback they get from these teachers reinforces the importance of good language in their work:

(1) I like my writing to be grammatically accurate. So, if she tells me something new about my grammar, maybe I am making consistent mistakes all the time and if she picks it out for me, it means I can like get rid of it because it's really bad to make a mistake and not know that it's a mistake.

(History)

Actually I am from the Mainland. Every time there is an English assignment all those from the Mainland will just, oh, there are so much work to do and we all chat about that and we often focus a lot on that because we think that English is very important. We all do a lot of language studies and look for the feedback.

(Business)

Many students, however, discover that grammar is not valued as much in their disciplines as they expected it would be. It seems to them that subject tutors focus on what the students have written about rather than the way they have written it and, by ignoring language errors, that they are implicitly signaling a more tolerant view of accurate presentation, as these quotes suggest:

(2) English courses have comments on language but Civil Engineering courses did not. They did not look at that. For example, we often have careless mistakes, like using wrong tenses, like something we did in a design but we write it in present tense. In fact, we have to use past tense. Civil Engineering professors would not give us feedback on 
this. They would give feedback like the units, abbreviations, calculations, etc.

(Civil Engineering)

I think the subject tutor usually expects your language is $\mathrm{OK}$ and they just concern about your data support or your logic or is your evidence convincing. They usually do not say too much about the language but of course if you can write more beautifully, it's better.

(Business)

The feedback is mainly on the subject content and how well I can apply the knowledge I learned in class. And before we write, our teacher already told us that our English doesn't matter, what matter is the application of knowledge. Of course, they will require you not to make many mistakes on it but that's just a basic requirement. We are expected to write something that he can understand is fine.

(Biology)

The message that many students take from this feedback is therefore that mistakes are acceptable as long as they don't undermine the meaning of the argument or the presentation of ideas. This view may simply reflect individual teachers' pessimistic assessments of the literacy skills of their students, but it is a useful corrective to students obsession with accuracy. It is also a message, however, which runs the risk of devaluing the importance of rhetorical approrpriacy in disciplinary argument. It says, in effect, that 'content' can be created independently of the language which conveys it: that meaning and form are separate things. It also seems to contain the message that the subject-specific conventions of disciplinary argument essentially boil down to issues of grammar, encouraging students to see the function of language support courses as learning decontextualised grammatical forms rather than understanding the communicative worlds of academic disciplines.

Writing, then, is often regarded as an autonomous skill rather than a disciplinary practice and equated to good grammar. Thus students acknowledge the importance of good writing as a means of engaging with readers, but often fail to make connections to disciplinary conventions: 
(3) I think English skill is not the most important one. It is a tool to present the ideas. For me in university level, I don't expect teachers to help me to improve my writing but they can give recommendations, advice on the ideas.

(American studies)

I think grammar is important in writing in two aspects because your writing is not just for yourself, it's something that you need to show other people. So, the first one is that with very good grammar with no grammatical mistake, you can leave a very good impression to one reading your essay. It's just like clear hand-writing. And for the other one, sometimes grammatical mistakes would affect the message that you want to tell the others.

(Psychology)

The messages students recover from their feedback regarding language also colours their view of the value of writing in the disciplines, as we shall see below.

\section{The role of writing in disciplinary communication}

Becoming literate in one's discipline essentially means developing an awareness of the functions of texts and how these functions are conventionally accomplished. By writing in their disciplines and receiving feedback on that writing, it is possible for students to learn that communication does not entail adherence to a set of universal rules but involves making rational choices based on the ways texts work in that specific context. Some students, however, appear to get the message that their teachers, in the hard fields at least, believe writing is less important than reproducing facts:

(4) I think the feedback is enough because in science we don't really need to write much. As an undergrad I only need to write lab reports.

(Biology)

For psychology there are seldom feedback from the course lecturers because even if they had any feedback, they would focus on the answer to the question and not the way we have written it. The language is not really right or wrong.

$$
\text { (Psychology) }
$$

I think for the essays related to my computer science major, I did not worry too much because what I have written is related to the technical knowledge and so I can easily 
do it. I can finish the task by copy and paste. I can write up the assignment without thinking.

(Computer science)

By providing very little advice on their assignments, these subject tutors convey the idea to students that writing is a straightforward matter and its conventions are self-evident. This message is reinforced in the classroom when written assignments are set:

(5) R: Are there any guidelines or handbooks that teach you how to write?

S: Not really, the teacher may give us an idea so in the lab report you have to have these sections, you have to have the aim and then you have to have result section and then discussion section. But we don't know what is included in each section.

(Chemistry)

The engineering teachers seldom teach us how to write the report. They just have a few words like which should be covered in the report, or the length the report should be. After that you just write it. So, actually, we all depend on our English course.

(Mechanical engineering)

While these understandings were often expressed by students studying hard science subjects, similar messages were picked up by those studying more social and applied subjects, as these quotes illustrate:

(6) R: Are there any guidelines from your teachers on how to write your essays?

S: For my Civil Engineering major, there is no such guideline because the lecturers just want us to answer questions. For the Business courses, the lecturers will lay out the instructions in the course outline in the first class. The guideline is very simple. It states that we should not have plagiarism, the format of the margin, the font size. It does not mention what you should do. It does not mention about the organization and the structure of the essay. $\quad$ (Business \& Civil engineering)

No. No advice on writing. Even if I ask I think he won't teach me much. I write it out myself by looking at the previous report samples and then put in the content. I believe he doesn't think it is difficult to write. (Social Administration)

No help about how to write. I think we are supposed to know what is wanted and write like that.

(Business) 
For many students in my sample this lack of explicit direction conveys the impression that academic writing conventions are unproblematically universal and unreflectively available. From it, students acquire the idea that the writing they are asked to do at university is simply an extension of the everyday literacies they bring with them from their homes. This then makes it harder for them to understand the complex ways in which discourse is situated in the social and epistemological practices of their disciplines.

\section{The role of writing in learning}

Tutors' feedback practices also convey messages to students about the role of writing in learning; whether this is learning about disciplinary content (e.g. Langer \& Applebee, 1987) or about appropriate conventions of writing itself (e.g. Christie \& Derewianka, 2008).

Feedback has considerable potential to raise students' awareness of the writing process itself as a means of developing control of the conventions of disciplinary writing practices. By requiring students to draft their assignments and then providing comments on these efforts, students can be encouraged to see the heuristic value of writing. Yet they largely experience this in their English classes:

(7) In the English class the tutor tried to help us to amend and then work on the draft but then for other courses, not much. Oh, one History course, the professor was very nice and he tried to help us. We can send him the draft and then he saw over some of the points. We can discuss with him but for most courses, they don't ask to give drafts.

(History)

For my English course, we write a first draft and the teacher would give feedback on it. By the time we get on the final draft, I am usually satisfied with that. But for the biochem course, the teachers don't take in draft. The thing you hand-in is the final version. I am more apprehensive about it, haha, what is going to turn out.

\section{(Biochemistry)}

Outside their academic literacy classes, students are rarely required to write several drafts of a paper. For some students the lack of the need to draft was seen positively and one actually believed it improved his language use: 
(8) Because of no draft I take care to write it well first time. I check my essay carefully and show my brother who is an English teacher. With a draft there is no need to be careful because the teacher will find all your error. It is easier to pass the assignment.

(Computer science)

Generally, however, this absence of a feedback-revision cycle appears to encourage a view among many students that they have nothing to learn from their written assignments, as these two students mentioned:

(9) There is no need to submit draft. Firstly, the workload will be heavier. Secondly, when we write essay, we only search for some information from the books and internet and then put them into the essay. I think it would be more efficient to write it out once.

(Biology)

No, not really satisfied with it, haha. Usually it is kind of last minute. I don't really take a lot of time to write it or correct it. So, it's not really organized very nicely.

(Electrical Engineering)

For many students, then, the absence of any focus on writing suggests that conventions are things to be picked up rather than learned and that writing is simply a means of assessment rather than a part of learning disciplinary forms of argument.

Thus writing becomes a practice of meeting criteria rather than of learning ways to create specific meanings. A number of students mentioned this as the purpose of the feedback they received:

(10) This is the criteria she gives before we write the essay and this tick means I met this criteria 'highly appropriate'. I get 'highly appropriate' and some of my friends get 'inappropriate'. And then after that she will see if we met other criteria. She will number that errors and she will highlight those errors.

(Economics)

I can read the criteria that she gives me and I will know what I should focus on and I should try my best to meet these criteria and also in my future writing. So I think it's really useful.

(Sociology) 
Similarly, while the role of writing in shaping content area learning has a long history in the UK and the US (e.g. Hirvela, 2011) students in Hong Kong are not familiar with the possibility that writing may be a way to acquire greater knowledge of a discipline's subject matter. The reluctance of many subject tutors to engage with students' ideas and understandings in their writing to foster such learning is apparent in the student interviews. In fact they often complained of long delays in retuning the paper:

(11) Usually there is not any discussion about the essay because it is a final essay, we don't see the professor any more. So we just get it back after the semester, haha.

(Social administration)

We hand-in the assignment in May and then it is summer holiday. You get a grade at the end, when the GPA is released. We can get back the essay and look at the grade and that's all.

(Business Studies)

I think it took him a long time to grade the essay because there are so many students in the class. So, it's at the end of the term when we almost forget we have written those essays.

(Computer science)

Feedback can help students to make sense of subject matter by seeing writing as a means of negotiating meaning with the tutor, but the working practices of most of the teachers in this sample convey the idea to students that writing is merely a summative activity. Students feel that subject tutors look at their writing as a final product rather than as a work in progress and an opportunity for instruction. Consequently, all but a few students in my sample believed that writing in their subject courses was a means of assessment rather than learning. Comments like this were rare indeed:

(12) I think writing is quite a good way for us to improve not only the writing skills but also how to think under that programme. For example, in the Modern China Studies programme, it emphasizes the China-centred approach, try to think under the nature of China, we have to emphasize the writing but also we need to learn more about the culture. So, I think it is a different way of thinking we can learn in the writing to study the course.

(Modern China Studies)

While the preceding discussion has focused on messages students discern about writing in their feedback, the final two messages concern their perceptions of the effects that tutor feedback can have. 


\section{The value of feedback to develop knowledge and skills}

A fourth message that students spoke of acquiring from feedback practices concerned the potential of feedback itself to contribute to learning. Students are accustomed to detailed error correction on their English writing at secondary school and have come to believe that this is an important aspect of their learning:

(13) I think comments help a lot because while we are writing we are standing in our own shoes, we are having our own certain point of view but the teacher, she is kind of distant from our angle. So, she could see how well we are doing. So, I think their comments are valuable. (American Studies)

They give feedback for improvement because writing is important in the university. You just hand-in all your words, your ideas in an essay. So, it is important for you to know what are your weaknesses and help you to improve by one essay and another essay.

(Sociology)

Feedback sometimes maybe inspire us to think from another angle on the same issue so that the content would be better, the organization would be better and that would also improve my skills.

(Politics \& Economics)

My interviews, however, echoed research which suggests students believe feedback comments could be more helpful (e.g. Weaver, 2006) and this is especially the case when discussing feedback on their subject assignments. There is a clear divide, in fact, in how students perceive their feedback from literacy and subject tutors:

(14) I think the feedback is so so. OK. because that helps me to improve my English but for the lab report, we usually ignore the comments. They are not useful.

(Biology)

For my English teacher, I think the feedback is really good. I am grateful because I think she really pay attention to my essay and she also tell me how can I improve. When I got my feedback from my subject teacher, I am happy that I get a high grade but also 
we all feel confused because he doesn't give feedback and I don't know what he likes in my essay or what he dislikes.

(Civil Engineering)

For my English teacher, it's enough but for my Business course, because there are a lot of students in the subject, our teachers don't give too much attention and he would give us a really general comment and grade but not very relevant comments.

(Business studies)

For many learners it is difficult to sustain a view that feedback is a potentially useful learning resource when their subject tutors give the impression that feedback has little value in the development of their subject knowledge or of a disciplinary-appropriate rhetorical competence. One way this is conveyed is through the absence of any detail in the teachers' responses:

(15) I don't think the teacher has much to tell us in feedback. From the feedback I get

I can't really think what the teachers want us to learn.

(Psychology)

$\mathrm{R}$ : What do you do when you get the assignment back?

S: Look at the grade.

$\mathrm{R}$ : And then?

S: Just look through the whole essay and see why I get the grade. Usually I cannot. Actually, I don't go to argue with the professor. Mostly I accept the grade.

(Computer science)

Chemistry teachers don't give comments. In psychology you only get the comments after your grade has come out, after GPA has been calculated and then they give you back your essay. Sometimes it may be the grade is not satisfactory but then the comment may be oh, this is good but they don't tell me what I am missing.

(Chemistry \& Psychology)

Handing back an assignment to students with just a bare grade or single word end-comment provides little usable information to help students improve their work or their understanding of the topic. This is a 
summative practice which implies to students that their work is an end in itself rather than a means to the acquisition of a specialist competence:

(16) I seldom receive feedback from the teachers of Social Administration. Usually they will just give us the grade. Sometimes they may underline the mistakes and they seldom write down anything for it. There is nothing they give us to improve. Just show the mistakes.

(Social Administration)

R: Have you learned anything from his feedback?

S: Not really. It's just a grade and one general comment and then OK, that's it.

(Electrical engineering)

$\mathrm{R}$ : What kind of comment do the the subject teachers give you?

$S$ : Just give us a grade.

$\mathrm{R}$ : Are there any general comments at the end?

S: No.

$\mathrm{R}:$ Only the grade?

S: Yes. That's Science. It tells the teacher if I know the content.

(Chemistry)

Students therefore often do not get feedback or when they do, tend to see it as perfunctory and unhelpful, perhaps implying a message from their tutors that feedback is unimportant. This is reinforced by the a perception that the same tutors are reluctant to organize post-feedback consultations to elaborate the grade and help them engage with the evaluations they have received. When tutors did suggest that students make an appointment to see them, however, this was sometimes met with a lack of enthusiasm: if teachers did not value feedback then why should they?

(17) I think a meeting with the teacher would be helpful because you can directly ask about what is your problem and how can I improve but they usually cannot spare time and many students are involved. So the students must approach teacher by ourselves. No one will do that because it's time consuming. (Business)

$\mathrm{R}$ : Is there a feedback session after they hand back the essay to you? 
S: Not really for Science, unless you actually go to the office and look for them, they are not going to talk about why it's marked like that. (Biochemistry)

Overall, this style of feedback communicates messages which are discouraging and perplexing to students, leading to negative views of feedback and the contribution it can make to learning. This is most clear in these extracts:

(18) The lecturers in Civil Engineering might be engineer in the past and some of them may just do research in lab and they might not see the importance of giving the feedback to the students and they may just think oh, if you can finish this question you are really good and that's enough. $\quad$ (Civil Engineering)

$\mathrm{R}$ : What have you learned from the feedback?

S: I usually don't take it very serious. I think it's just an assignment and just try and complete it as nicely as I can.

(Biology)

R: Do you think the comments are useful for your future writing?

S: No because we usually write different areas or different kinds of assignment so the comments are only helpful for the finished essay. What can I learn about other essays?

(Sociology)

In these ways, then, students come to regard feedback as relatively unimportant to their learning and understand their teachers to see it as simply an acknowledgement of a completed assessment task.

\section{The nature of the teacher-student relationship}

Finally, at the same time students are acquiring impressions of how their teachers might understand writing and their attitudes to teaching and learning from feedback, they also glean information about the nature of the teacher-student relationship itself. Embedded in tutors' feedback practices are messages concerning relative power-distance dynamics and how teacher-student interactions should be conducted. 
Research suggests that effective feedback is a response to the writing of a particular student, given as part of the teacher's recognition of that student's needs and preferences and reflecting an understanding of a classroom relationship (e.g. Hyland \& Hyland, 2001). How students respond to feedback, and the messages they take from it, are therefore likely to be influenced by who the teacher is and whether it is given with him or her in mind. The students in this study said that they welcomed individual attention and saw in it the teacher's attempts to personally relate to him or her:

(19) The English teacher specified she will spend 5 minutes for each student to talk about the comments after the class. I think this is a good idea and it is a big help to me with the essay. It also helps the teacher to know about my weaknesses and to know about me. The subject teacher doesn't do this.

(History)

I think it is better when we can discuss with our teachers. I think our teachers can be active to be interest in me and give me personal feedback or discuss more personally with us instead of just a grade. $\quad$ (Economics)

If the teacher gives you many feedbacks, you will feel very touched, that they care about you as a student. I read it and make corrections and remember it. It is a pleasure for me.

(English)

We need to remember that the views expressed in these quotes may be, in part, shaped by the interview context, but students do seem discouraged by the relationships fashioned by the many of the practices discussed in this paper. Providing an unadorned grade, delaying the return of papers and failing to discuss comments with students suggest to students that their teachers believe it is not worth engaging in a dialogue with them on their writing. It signals what appears as an aloof and uninterested stance towards them, as several students mentioned:

(20) My business tutor just give me one line comment usually and doesn't care. We are too many to care about us.

(Business Studies) 
Actually for the Science courses professors will not mark our lab reports by themselves. They will ask their postgraduates, our demonstrators, to mark our lab reports. They don't know our work or us.

(Chemistry)

The demonstrators mark the essay. We don't know the professor very well.

(Biology)

Students report their impression that their teachers are busy people overburdened with research and too many students. The feedback practices they encounter convey a strong message that students occupy a relatively low position in their teachers' priorities:

(21) She did say that we can find her if we have any problems or questions about the marking but often I have a class which clashed with the consultation hour so I would just ask her after class. There is no time and she is in a hurry. I don't feel happy about it. (European Studies)

The Computer science tutors don't have much time to communicate with us. Only in class. And anyway, because it's a report, we just write facts.

\section{(Computer Science)}

I sometimes contact them by email but not about the feedback. Usually they are too busy to talk about the essay. They have research to do.

(Sociology)

In many cases, then, feedback is perceived as generic and unrelated to the personalities and learning needs of students. Writing comes to be seen as an assessment tool and feedback as a means of checking student understanding rather than of a springboard for learning and a way of building supportive relationships with students.

\section{Conclusions, implications and limitations}

While feedback research has tended to address the practices of teachers, I have sought to shift attention to the meanings students take from these practices. Where feedback is perceived as timely, individualised and focused it conveys encouragement and a sense of the importance of writing, but where it is seen as 
perfunctory, delayed and unrelated to their individual needs, these messages are negative and fail to support students' efforts to master academic writing practices.

Quality feedback supports learning by revealing any gap between students' current performance and expected levels of achievement and by assisting them to take actions to narrow that gap (e.g. Bitchener, 2008; Bloxham and Boyd, 2007; Hattie \& Timperley, 2007). But because these students are rarely provided with feedback which helps them to conceptualize the varied epistemological frameworks of the academy, students are often unable to see how these relate to disciplinary communication. By detaching academic literacy from disciplinary beliefs and practices, both learners and teachers may come to see literacy practices as autonomous, abstract and beyond students' control and thus to see communication difficulties as learners' own weaknesses. This study suggests that the overriding message that students take from their tutors' feedback is that academic literacy is an abstract and relatively self-evident style of writing unrelated to particular academic communities. By treating language as unproblematic, students read their feedback as separate from the contexts in which they are asked to write and come to believe that they simply have to master a set of rules which can be transferred across fields.

I should mention that there are limitations to this research. First, we need to be cautious in interpreting interview data and keep in mind the distinction between a particular reality, students' perceptions of that reality and their communication of these perceptions to a researcher. What individuals say in an interview may be a partial, even idealized, version of themselves as students, possibly hiding a desire to simply get a grade and get on with their lives. This is not to be disrespectful to students who, like all of us, are often pressed for time and have other commitments.

My sense while interviewing, however, was that students were expressing themselves as honestly as possible in what feedback meant to them. Second, there is also the issue that students' interpretations may be based on unrealistic expectations rather than their teachers' actual practices. There is, however, 
sufficient uniformity in these views to generalise. It is certainly a common belief among students that their tutors tend to focus on correcting misunderstandings in the current text rather than seeing writing developmentally or feedback as an opportunity to encourage learning. Finally, it is worth pausing to consider how far these student impressions are more generalizable beyond this second language setting. While researchers in other contexts have noted the importance of student perceptions on learning (e.g. Orsmond \& Merry, 2011; Pokorny \& Pickford, 2010), I cannot claim this context is not unusual.

While perhaps discouraging, these findings also suggest some ways forward. Clearly feedback research of this kind should not prescribe general practices which may not fit other contexts: first language needs, university differences and disciplinary variations all contribute to a range of expectations and behaviours. There is, however, a need for greater alignment between student expectation and tutor practice which can only be achieved through dialogue and training. It is helpful if agreement on what students want and what tutors expect from feedback is established at the beginning of any course. Moreover, the interviews here suggest that students generally read more positive messages into the feedback they received from language tutors, a group who not only tend to be less burdened than their faculty counterparts by publishing pressures, heavy administrative loads and large classes, but who are invariably trained teachers. Teachers should be encourage to reflect on their feedback and consider its use to better scaffold learning in formal mentoring schemes and CPD workshops and its incorporation into professional development programmes such as those accredited by the Staff and Educational Development Association (SEDA) in the UK are to be welcomed.

What is imperative is that feedback cannot be seen as a separate and isolated event that happens on the return of assignments, simply given and forgotten. While its efficacy in improving students' writing or their understanding of disciplinary concepts may be disputed, the messages which underlay the provision of feedback are equally important and may even be more enduring. 


\section{References}

Bitchener, J. (2008). Evidence in support of corrective feedback. Journal of Second Language Writing, 17: $102-118$.

Bloxham, S. \& Boyd, P. (2007) Developing Effective Assessment in Higher Education. Maidenhead: Open University Press.

Carless, D. (2006). Differing perceptions in the feedback process. Studies in Higher Education. 32 (2): 219-233.

Christie, F. \& Derewianka, B. (2008). School Discourse. London: Continuum.

Davison, C. (2007). Views from the chalkface: English language school-based assessment in Hong Kong. Language Assessment Quarterly. 4 (1): 37-68.

Ferris, D. (2006). Does error feedback help student writers? New evidence on the short- and long-term effects of written error correction. In K. Hyland \& F. Hyland (eds.).

Goffman, E. (1971) The Presentation of Self in Everyday Life, Harmondsworth: Penguin Books.

Hattie, J. \& Timperley, H. (2007). The power of feedback. Review of Educational Research. 77 (1): 81112.

Higgins, R., Hartley, P. \& Skelton, A. (2001). Getting the message across: the problem of communicating assessment feedback. Teaching in Higher Education. 6 (2): 269-74.

Hirvela, A. (2011). Writing to learn in content areas. In R. Manchón (ed.) Learning-To-Write and Writing-To-Learn in an Additional Language. Amsterdam: Benjamins

Hu, G. W. (2005). Contextual influences on instructional practices: A Chinese case for an ecological approach to ELT. TESOL Quarterly 394, 635-660

Hyland, F. (2010). Future directions in feedback on second language writing: Overview and research agenda. International Journal of English Studies 10.2, 171-182.

Hyland, F. \& K. Hyland (2001). 'Sugaring the pill; Praise and criticism in written feedback. Journal of Second Language Writing 10.3, 185-212. 
Hyland, K. \& F. Hyland (2006). Interpersonal aspects of response: constructing and interpreting teacher written feedback. In K. Hyland \& F. Hyland (eds.). Feedback in Second Language Writing: Contexts and Issues. New York: Cambridge University Press.

Krause, K.L., Hartley, R. James, R. McInnis, C. (2005). The first year experience in Australian universities: Findings from a decade of national studies. http://www.griffith.edu.au/data/assets/pdf_file/0006/37491/FYEReport05.pdf (accessed 4/6/2012).

Langer, J. \& Applebee, A. (1987). How Writing Shapes Thinking: A Study of Teaching and Learning. NCTE Research Report No. 22. http://eric.ed.gov/PDFS/ED286205.pdf (accessed 4/6/2012).

Lea, M. and Street, B. V. (2000) 'Student writing and staff feedback in higher education', in M. Lea and B. Stierer (eds.), Student Writing in Higher Education: New Contexts (pp. 32-46), Buckingham: SRHE and Open University Press.

Lee, I. (2008). Understanding teachers' written feedback practices in Hong Kong secondary classrooms. Journal of Second Language Writing. 17: 69-85.

Orsmond \& Merry, (2011) Feedback alignment: effective and ineffective links between tutors' and students' understanding of coursework feedback. Assessment \& Evaluation in Higher Education. 36 (2) $125-136$.

Pokorny, H. \& Pickford, P. (2010). Complexity, cues and relationships: Student perceptions of feedback. Active Learning in Higher Education. 11 (1): 21-30

Price, M., Handley, K., Millar, J. \& O’Donovan, B. (2010). Feedback: all that effort, but what is the effect? Assessment and Evaluation in higher Education. 35 (3): 277-289.

Schulz, R. A. (2001). Cultural Differences in Student and Teacher Perceptions concerning the Role of Grammar Instruction and Corrective Feedback: USA-Columbia. The Modern Language Journal. 85 (2), pp. $244-258$ 
Scott, J., Badge, J. \& Cann, A. (2009). Perceptions of Feedback One Year On: A Comparative Study of the Views of First and Second Year Biological Sciences Students. Bioscience Education.vol. 13. www.bioscience.heacademy.ac.uk/journal/vol13/beej-13-2.pdf

Truscott, J. (1996). The case against grammar correction in L2 writing classes. Language Learning 46.2, $327-369$.

Truscott, J. \& Hsu, A. Y.P. (2008). Journal of second Language Writing. 17: 292-305.

Vygotsky, L. (1978). Mind in society: the development of higher psychological processes. Cambridge. MA: Harvard University Press.

Walker, M. (2009). An investigation into written comments on assignments: do students find them usable? Assessment \& Evaluation in Higher Education. 34 (1): 47-78.

Watty, K, Carr, R, De Lange, P, O'Connell, B and Howieson, B 2011, 'Student perceptions of feedback in Australian University accounting education', in Brad Potter and Paul De Lange (ed.) Proceedings of 2011 AFAANZ Conference, Carlton, Australia, 2-5 July, 2011, pp. 1-33.

Weaver, M. (2006). Do students value feedback? Student perceptions of tutors' written responses. Assessment \& Evaluation in Higher Education. 31 (3): 379-394.

Yorke, M. (2003) Formative assessment in higher education: moves towards theory and the enhancement of pedagogic practice. Higher Education 45(4): 471-501. 